\title{
Clinical efficacy evaluation of tyrosine kinase inhibitors for non-adenocarcinoma lung cancer patients harboring EGFR-sensitizing mutations
}

This article was published in the following Dove Press journal:

OncoTargets and Therapy

22 June 2017

Number of times this article has been viewed

\author{
Xinyu Song' \\ Zhehai Wang² \\ 'School of Medicine and Life Sciences, \\ University of Jinan-Shandong Academy \\ of Medical Sciences, ${ }^{2}$ Shandong \\ Cancer Hospital Affiliated to \\ Shandong University, Jinan, Shandong, \\ People's Republic of China
}

\begin{abstract}
Epidermal growth factor receptor (EGFR) tyrosine kinase inhibitors (TKIs) as a standard therapy have been used in EGFR-mutated adenocarcinoma of non-small-cell lung cancer (NSCLC) patients in recent years. But in current randomized prospective clinical trials, due to few cases of non-adenocarcinoma patients having been found, the efficacy of TKIs for EGFR-mutated non-adenocarcinoma and the relationship with clinicopathological characteristics remained debatable. The results of retrospective studies showed that the frequency of EGFR mutation was significantly associated with nationality, gender, smoking history, and histology type. Being female, never-smoker and adenocarcinoma had a higher mutation rate. Furthermore, the EGFR mutation rate and efficacies of TKIs in adenocarcinoma were higher than those in non-adenocarcinoma. And in non-adenocarcinoma, the EGFR mutation rate and efficacies of TKIs in adenosquamous cell carcinoma were higher than those in squamous cell carcinoma or in large-cell lung carcinoma. In conclusion, it may be necessary to conduct a large sample prospective study to understand the clinicopathological characteristics of nonadenocarcinomas and to evaluate the efficacy of EGFR TKI and/or chemotherapy for EGFRmutated non-adenocarcinoma NSCLC. So we searched relevant articles between the year 2010 and 2016 through the major indexed literature database PubMed by searching the keywords such as EGFR mutation, Tyrosine kinase inhibitors, and Non-adenocarcinoma.
\end{abstract}

Keywords: EGFR mutation, tyrosine kinase inhibitors, non-adenocarcinoma

\section{Introduction}

The incidence and mortality of lung cancer accounted for a very large proportion in malignant tumor on a global scale. Non-small-cell lung cancer (NSCLC) accounts for about $85 \%$ of all lung cancers, and about $70 \%$ of patients with NSCLC are primarily diagnosed at late stage, which results in poor prognosis. ${ }^{1}$ In the last decade, the discovery of epidermal growth factor receptor (EGFR) and the remarkable efficacy of tyrosine kinase inhibitors (TKIs) in patients with EGFR mutations made a big change in the treatment methods of adenocarcinoma and gradually opened the era of NSCLC precise molecular target therapy. ${ }^{2,3}$

EGFR mutations were significantly associated with nationality, gender, smoking history, and histology type. ${ }^{4}$ EGFR mutation rate in mainland Chinese NSCLC patients was $36.2 \%-50.2 \%$, significantly higher than that of other histological types. ${ }^{5,6}$ There were seven Phase III randomized clinical study reports during 2010-2014, which compared EGFR TKIs and chemotherapy in advanced NSCLC patients. One thousand six hundred forty-nine patients with EGFR mutations enrolled, of which adenocarcinoma patients accounted for $95.9 \%$ and non-adenocarcinoma patients
Shandong Cancer Hospital Affiliated to Shandong University, Jiyan Rd. 440, Jinan 250I I7, Shandong Province 250II7, People's Republic of China

Tel +8653 I 67626332

Fax +8653167626332

Email wzhai8778@sina.com 
Table I Efficacy of TKIs in EGFR-mutated non-adenocarcinoma

\begin{tabular}{|c|c|c|c|c|}
\hline Author & Total cases & TKIs & $\begin{array}{l}\text { Response } \\
\text { rate }(\%)\end{array}$ & PFS (months) \\
\hline Shukuya et al ${ }^{16}$ & $\begin{array}{l}20(\mathrm{ASC}=2, S C C=16, \mathrm{LCLC}=1 \text {, } \\
\text { pleomorphic carcinoma }=1)\end{array}$ & G & 35.0 & 3.1 \\
\hline Cho et $\mathrm{al}^{10}$ & $12(\mathrm{ASC}=3, \mathrm{SCC}=8$, others $=1)$ & $\mathrm{G}, \mathrm{E}$ & 50.0 & 3.67 \\
\hline Zeng et $\mathrm{al}^{17}$ & $6(\mathrm{ASC}=3, \mathrm{SCC}=3)$ & $\mathrm{G}, \mathrm{E}$ & 100.0 & 9.2 \\
\hline Xu et al $^{9}$ & $\begin{array}{l}51(\mathrm{ASC}=15, \mathrm{SCC}=26 \\
\mathrm{LCLC}=10)\end{array}$ & G, E, I & 39.2 & $\begin{array}{l}\mathrm{SCC}=3.98, \mathrm{ASC}=8.08 \\
\mathrm{LCLC}=4.40\end{array}$ \\
\hline
\end{tabular}

Abbreviations: ASC, adenosquamous cell carcinoma; EGFR, epidermal growth factor receptor; E, erlotinib; G, gefitinib; I, icotinibwen; LCLC, large-cell lung carcinoma; PFS, progression-free survival; SCC, squamous cell carcinoma; TKls, tyrosine kinase inhibitors.

accounted for $4.1 \% .^{7}$ Current clinical studies of EGFR mutations mainly concentrated on lung adenocarcinoma, and the clinical pathology factors of EGFR mutations and the correlation with TKI treatment research of non-adenocarcinoma were both inadequate.

\section{Efficacy evaluation of TKIs in EGFR- mutated non-adenocarcinomas}

In the present retrospective reports, non-adenocarcinoma NSCLC included squamous cell carcinoma, adenosquamous cell carcinoma, large-cell lung carcinoma, sarcomatoid carcinoma, pleomorphic carcinoma, and some other rare types. A meta-analysis in 2014 included 5,442 patients from 21 studies. $^{8}$ The overall EGFR mutation rate was 37.5\% $(2,039 / 5,442)$. Patients with adenocarcinoma had a higher mutation rate than those with non-adenocarcinoma $(50.2 \%$ vs $17.0 \%, P<0.001)$. A retrospective analysis in 2016 tested 597 non-adenocarcinoma NSCLC patients, ${ }^{9}$ and the EGFR mutation rate was $12.9 \%$. Cho et al reported 1,255 patients with advanced NSCLC who accepted gefitinib at Samsung Medical Center between January 2007 and July $2010 .{ }^{10}$ A total of $77.7 \%$ (209/269) of adenocarcinoma patients with EGFR mutation achieved complete or partial response to EGFR TKIs, and the median progress free survival (mPFS) of them was 11.27 months, while the response rate of non-adenocarcinoma patients harboring EGFR mutation was 50\% (6/12), and the mPFS of them was 3.67 months. The progression-free survival (PFS) between these two groups was significantly different $(P<0.001)$. In non-adenocarcinoma, different histology types may accept different efficacy (Table 1).

As we know, exon 19 deletion (del19) and an exon 21 L858R (L858R) mutation are the two most common EGRF mutations occurring in NSCLC. Liu et al reported a metaanalysis in 2016, according to which advanced NSCLC patients, who had a del19, may acquire higher overall response rate, PFS, and overall survival after using TKIs compared with the one who had an L858R mutation. ${ }^{11}$
However, up to now, there is no literature that has reported the difference between del19 and L858R after EGFR-TKIs treatment in non-adenocarcinoma lung cancer patients. Hence, in our review, we just discussed the EGRF mutation as an overall concept rather than separating it as del19 and L858R.

\section{Efficacy evaluation of TKIs in EGFR- mutated squamous carcinomas}

In four retrospective literature where the baseline data of patients were relatively intact, we could see that the mutation rate of squamous carcinoma was $4.31 \%-17.20 \%$ (Table 2 ). When testing a total of 1,084 squamous carcinoma patients using ARMS method, 104 of them had EGFR mutation, and the mutation rate was $9.59 \% .{ }^{8}$ In squamous carcinomas, the frequency of EGFR mutation was also associated with gender and smoking history. Zhang et al reported that the EGFR mutation rate of squamous carcinoma was $12.3 \%$ in men and $28.6 \%$ in women $(P=0.022) .{ }^{14}$ The EGFR mutation rate of squamous carcinoma was $26.2 \%$ in never-smokers and was $11.5 \%$ in smokers $(P=0.049)$. The efficacy of TKIs in EGFR-mutated squamous carcinoma was not very good, the response rate was $26.7 \%-38.0 \%$, and the mPFS was 3.1-3.98 months (Table 3). Xu et al tested EGFR mutation in 597 non-adenocarcinoma NSCLC patients, ${ }^{9}$ and the squamous carcinomas among them were 457 . The number of patients harboring EGFR mutation was 47, and 26 patients among them accepted TKIs (including gefitinib, erlotinib,

Table 2 The mutation rate of lung squamous carcinoma

\begin{tabular}{llll}
\hline Author & $\begin{array}{l}\text { All patients } \\
\text { screened for } \\
\text { EGFR mutations }\end{array}$ & $\begin{array}{l}\text { Patients } \\
\text { with EGFR } \\
\text { mutations }\end{array}$ & $\begin{array}{l}\text { Proportion } \\
\text { (\%) }\end{array}$ \\
\hline Fang et al $^{12}$ & 209 & 18 & 8.61 \\
Zhang et al $^{14}$ & 163 & 28 & 17.2 \\
Xu et al $^{9}$ & 457 & 47 & 10.28 \\
Wen et al $^{13}$ & 255 & $1 \mathrm{l}$ & 4.31 \\
\hline
\end{tabular}

Abbreviation: EGFR, epidermal growth factor receptor. 
Table 3 Efficacy of TKIs in EGFR-mutated squamous carcinoma

\begin{tabular}{lllll}
\hline Author & $\begin{array}{l}\text { Total } \\
\text { cases }\end{array}$ & TKIs & $\begin{array}{l}\text { Response } \\
\text { rate (\%) }\end{array}$ & $\begin{array}{l}\text { PFS } \\
\text { (months) }\end{array}$ \\
\hline Shukuya et al $^{16}$ & 16 & G & 38.0 & 3.1 \\
Cho et al $^{10}$ & 8 & G, E & 37.5 & 4.1 \\
Fang et al $^{12}$ & I5 & G, E & 26.7 & 3.9 \\
Xu et al $^{9}$ & 26 & G, E, I & 30.8 & 3.98 \\
\hline
\end{tabular}

Abbreviations: E, erlotinib; EGFR, epidermal growth factor receptor; G, gefitinib I, cotinibwen; PFS, progression-free survival; TKls, tyrosine kinase inhibitors.

and icotinib); the response rate was $30.8 \%$ and the mPFS was 3.98 months. Fang et al treated 63 patients with squamous carcinoma using gefitinib or erlotinib. ${ }^{12}$ The number of patients harboring EGFR mutation was 15 . The response rate of 15 patients was $26.7 \%$ and the mPFS was 3.9 months.

\section{Efficacy evaluation of TKIs in EGFR-mutated adenosquamous carcinomas}

Most reports about EGFR-mutated adenosquamous carcinoma were from subgroup analysis of retrospective study, and the sample size was less. Wen et al tested postoperative fresh specimens of 694 NSCLC patients using ARMS method; ${ }^{13} 68$ among them were adenosquamous carcinoma, and 17 adenosquamous carcinoma patients had EGFR mutation and the mutation rate was $25 \%$. Xu et al tested the EGFR status of 597 non-adenocarcinoma patients; ${ }^{9} 43$ among them were adenosquamous carcinoma, and 18 patients had EGFR mutation and the mutation rate was $41.86 \%$ (Table 4 ). Shukuya et al made a pooling analysis of the published literature in 2005-2009, ${ }^{16}$ including five prospective and 10 retrospective studies. Among 33 non-adenocarcinoma patients harboring EGFR mutation, only two patients had EGFR-mutated adenosquamous carcinoma and only one patient accepted response to TKIs, and the mPFS was 5.3 months. Cho et al treated three patients with EGFR-mutated adenosquamous carcinoma using gefitinib or erlotinib as second-line therapy, ${ }^{10}$ all of them accepted partial response, and the mPFS was 4.53, 8.23 , and 13.53 months, respectively. Xu et al published a retrospective analysis in $2016 ;{ }^{9}$ totally, 15 patients with EGFR-mutated adenosquamous carcinoma were reported,

Table 4 The mutation rate of lung adenosquamous carcinoma

\begin{tabular}{llll}
\hline Author & $\begin{array}{l}\text { All patients } \\
\text { screened for } \\
\text { EGFR mutations }\end{array}$ & $\begin{array}{l}\text { Patients } \\
\text { with EGFR } \\
\text { mutations }\end{array}$ & $\begin{array}{l}\text { Proportion } \\
\text { (\%) }\end{array}$ \\
\hline Xu et al $^{9}$ & 43 & 18 & 41.86 \\
Shukuya et al $^{16}$ & 33 & 2 & 6.1 \\
Wen et al $^{13}$ & 68 & 17 & 25 \\
\hline
\end{tabular}

Abbreviation: EGFR, epidermal growth factor receptor.
Table 5 Efficacy of TKIs in EGFR-mutated adenosquamous carcinoma

\begin{tabular}{lllll}
\hline Author & $\begin{array}{l}\text { Total } \\
\text { cases }\end{array}$ & TKIs & $\begin{array}{l}\text { Response } \\
\text { rate (\%) }\end{array}$ & $\begin{array}{l}\text { mPFS } \\
\text { (months) }\end{array}$ \\
\hline Shukuya et al $^{16}$ & 2 & G & 50.0 & 5.3 \\
Cho et al $^{10}$ & 3 & G, E & 100.0 & 8.23 \\
Xu et al $^{9}$ & I5 & - & 60.0 & 8.08 \\
\hline
\end{tabular}

Abbreviations: E, erlotinib; EGFR, epidermal growth factor receptor; G, gefitinib; TKIs, tyrosine kinase inhibitors; mPFS, median progress free survival.

nine patients among them accepted partial response, and the response rate was $60 \%(9 / 15)$ and the MPFS was 8.08 months (Table 5).

\section{Efficacy evaluation of TKIs in other non-adenocarcinoma types harboring EGFR mutation}

Other non-adenocarcinoma NSCLC types included largecell carcinoma, sarcomatoid carcinoma, mucoepidermoid carcinoma, and so on, but the relevant reports were rare. Enewol and Thomas reported the actual state of EGFR test among 1,358 NSCLC patients in America, ${ }^{15}$ and the largecell carcinoma accounted for only $1.3 \%$. When testing the gene from postoperative fresh specimens of 694 NSCLC patients using ARMS method, ${ }^{13}$ large-cell carcinoma and sarcomatoid carcinoma were only 56 cases $(8.07 \%)$, and the EGFR mutation rate among them was $8.93 \%$. Shukuya et al reported one large-cell carcinoma case, one pleomorphic carcinoma case, and one spindle cell carcinoma case,${ }^{16}$ they both accepted the therapy of gefitinib, but none of them accepted the response. Xu et al reported the EGFR testing outcome of 597 non-adenocarcinoma patients, ${ }^{9} 97$ patients were large-cell carcinoma, 12 patients among them harbored EGFR mutation, and the mutation rate was $12.37 \%$. Ten patients among them accepted the therapy of TKIs as first or second line, and only three patients accepted partial response; the response rate was $30 \%$ and mPFS was 4.4 months. Above all, the efficacy of TKIs in other non-adenocarcinoma types harboring EGFR mutation was not very good.

\section{Conclusion}

The above comparison and analysis illustrated that the EGFR mutation rate of non-adenocarcinoma was lower than that of adenocarcinoma. In non-adenocarcinoma, the efficacy of TIKs in adenosquamous carcinoma was better than that of large-cell carcinoma or sarcomatoid carcinoma. Now the present problems in current studies of EGFRmutated non-adenocarcinoma are mainly concentrated on the following: 1) the determination of pathological histology 
and EGFR testing standards. How to determine or exclude adenocarcinoma ingredients, which may be mixed in some non-adenocarcinoma types, especially when the tissue sample size decreased, which is hard to avoid in the clinical practice. 2) The sample of retrospective studies is generally small, and the EGFR testing method is not entirely consistent. 3) Lack of research evidence about the efficacy of TKIs to nonadenocarcinoma harboring different exons mutation. 4) Lack of efficacy analysis of chemotherapy in these patients. Although the study of EGFR mutation of adenocarcinoma NSCLC still exist some problems, but the existing research results that the incidence of EGFR mutations in nonadenocarcinoma NSCLC was not very low in a Chinese population. Thus, EGFR TKIs could be an option for the treatment of EGFR-mutated non-adenocarcinoma NSCLC. It is necessary to conduct a large sample prospective study to evaluate the efficacy of EGFR TKIs in EGFR-mutated non-adenocarcinoma NSCLC, so that we could get more supporting data on TKI treatment in non-adenocarcinoma patients with EGFR mutations.

\section{Disclosure}

The authors report no conflicts of interest in this work.

\section{References}

1. Jemal A, Siegel R, Ward E, Hao Y, Xu J, Thun MJ. Cancer statistics, 2009. CA Cancer J Clin. 2009;59(4):225-249.

2. Mok TS, Wu YL, Thongprasert S, et al. Gefitinib or carboplatinpaclitaxel in pulmonary adenocarcinoma. $N$ Engl J Med. 2009;361: 947-957.

3. Maemondo M, Inoue A, Kobayashi K, et al. Gefitinib or chemotherapy for non-small-cell lung cancer with mutated EGFR. N Engl J Med. 2010; 362(25):2380-2388.

4. Tanaka T, Matsuoka M, Sutani A, et al. Spanish Lung Cancer Group. Frequency of and variables associated with the EGFR mutation and its subtypes. Int J Cancer. 2010;126(3):651-655.

5. Wen MM, Wang XJ, Sun Y, et al. Detection of EML4-ALK fusion gene and features associated with EGFR mutations in Chinese patients with non-small-cell lung cancer. Onco Targets Ther. 2016;9:1989-1995.
6. Shi YK, Li JL, Zhang SC, et al. Molecular Epidemiology of EGFR Mutation Asian Patients with Advanced Non-Small-Cell Lung Cancer of Adenocarcinoma Histology - Mainland China Subset Analysis of the PIONEER Study. PLoS One. 2015;10(11):e0143515.

7. Lee CK, Wu YL, Ding PN, et al. Impact of Specific Epidermal Growth Factor Receptor (EGFR) mutations and clinical characteristics on outcomes after treatment with EGFR tyrosine kinase inhibitors versus chemotherapy in EGFR-mutant lung cancer: a meta-analysis. Clin Oncol. 2015;33(17):1958-1965.

8. Wang S, Wang Z. EGFR mutations in patients with non-small cell lung cancer from mainland China and their relationships with clinicopathological features: a meta-analysis. Int J Clin Exp Med. 2014;7(8): 1967-1978.

9. Xu J, Zhang Y, Jin B, et al. Efficacy of EGFR tyrosine kinase inhibitors for non-adenocarcinoma lung cancer patients harboring EGFRsensitizing mutations in China. J Cancer Res Clin Oncol. 2016; 142(6):1325-1330.

10. Cho SH, Park LC, Ji JH, et al. Efficacy of EGFR tyrosine kinase inhibitors for non-adenocarcinoma NSCLC patients with EGFR mutation. Cancer Chemother Pharmacol. 2012;70(2):315-320.

11. Liu Y, Ren Z, Wang J, et al. Epidermal growth factor receptor-tyrosine kinase inhibitor therapy is especially beneficial to patients with exon 19 deletion compared with exon 21 L858R mutation in non-small-cell lung cancer: systematic review and meta analysis. Thorac Cancer. 2016; 7(4):406-414

12. Fang W, Zhang J, Liang WL, et al. Efficacy of epidermal growth factor receptor-tyrosine kinase inhibitors for Chinese patients with squamous cell carcinoma of lung harboring EGFR mutation. J Thorac Dis. 2013;5(5):585-592.

13. Wen M, Wang X, Sun Y, et al. Detection of EML4-ALK fusion gene and features associated with EGFR mutations in Chinese patients with non-small-cell lung cancer. Onco Targets Ther. 2016;9:1989-1995.

14. Zhang Q, Zhu L, Zhang J. Epidermal growth factor receptor gene mutation status in pure squamous-cell lung cancer in Chinese patients. BMC Cancer. 2015;15:88.

15. Enewold L, Thomas A. Real-world patterns of EGFR testing and treatment with erlotinib for non-small cell lung cancer in the United States. PLoS One. 2016;11(6): 0156728.

16. Shukuya T, Takahashi T, Kaira R, et al. Efficacy of gefitinib for nonadenocarcinoma non-small-cell lung cancer patients harboring epidermal growth factor receptor mutations: a pooled analysis of published reports. Cancer Sci. 2011;102(5):1032-1037.

17. Zeng Z, Chen HJ, Yan HH, et al. Sensitivity to epidermal growth factor receptor tyrosine kinase inhibitors in males, smokers, and nonadenocarcinoma lung cancer in patients with EGFR mutations. Int $J$ Biol Markers. 2013;3:249-258.
OncoTargets and Therapy

\section{Publish your work in this journal}

OncoTargets and Therapy is an international, peer-reviewed, open access journal focusing on the pathological basis of all cancers, potential targets for therapy and treatment protocols employed to improve the management of cancer patients. The journal also focuses on the impact of management programs and new therapeutic agents and protocols on

\section{Dovepress}

patient perspectives such as quality of life, adherence and satisfaction. The manuscript management system is completely online and includes a very quick and fair peer-review system, which is all easy to use. Visit $\mathrm{http}: / /$ www.dovepress.com/testimonials.php to read real quotes from published authors. 